Козырева М.К.

\section{НЕКОТОРЫЕ ОСОБЕННОСТИ ВЕРБАЛИЗАЦИИ КОНЦЕПТА «MUSLIM WORLD» В ВИРТУАЛЬНОМ КОММУНИКАТИВНОМ ПРОСТРАНСТВЕ}

Федеральное государственное автономное образовательное учреждение высшего образования «Белгородский государственный национальный исследовательский университет» (НИУ «БелГУ») ул. Победы, 85, г. Белгород, 308015, Россия, goodluck_flovers@ @ail.ru

\begin{abstract}
Аннотация. В статье речь идет о некоторых особенностях репрезентации концепта «Muslim World» в виртуальном медиа-дискурсе. Статья напрямую затрагивает изучение проблемы отношений между сторонами «Запад-Восток». Помимо этого, представлен анализ языковых единиц, которые являются номинативными для обозначения концепта «Muslim World», также обозначены признаки данного концепта. Автор проводит анализ коммуникативных стратегий манипуляционного характера, которые используется для актуализации концепта «Muslim World» в массовом сознании. Фактическим материалом исследования были выбраны ведущие популярные англоязычные масс-медиа. Исследуя статьи Al Jazeera: Live News, CNN International edition, комментарии к официальным материалам, автор приходит к выводу о том, что в общении семантическая нагрузка концепта объективируется посредством использования негативной коннотации.
\end{abstract}

Ключевые слова: «Исламский мир»; концепт; терроризм; коннотация, исламофобия.

\title{
Kozyreva M. K. \\ SOME FEATURES OF VERBALIZATION OF THE CONCEPT «MUSLIM WORLD» IN VIRTUAL COMMUNICATIVE SPACE
}

Belgorod State National Research University, 85 Pobedy St., Belgorod, 308015, Russia, goodluck_flovers@mail.ru

\begin{abstract}
The article deals with some features of representation of the concept "Muslim World" in a virtual media discourse. The article directly involves the study of the problem of "West-East" relations. In addition, the analysis of linguistic units which are nominative for the designation of the concept "Muslim World" is presented, and the features of this concept are also indicated. The analysis of communicative strategies of the manipulative nature that are used to update the concept "Muslim World" in the mass consciousness was carried out. The material of the study was popular English mass media. Studying some articles from Al Jazeera: Live News, CNN International edition, comments on the official materials, the author comes to the conclusion the semantic load of the concept is objectified through the use of negative connotation.
\end{abstract}

Key words: Muslim world; concept; terrorism; connotation, Islamophobia.

\section{Введение.}

Глобальная компьютерная сеть является сегодня новой средой общения, где есть отличная возможность для самореализации как в профессиональном, так и в личном аспектах. По своей сути, Интернет является

\begin{abstract}
платформой для выражения реального отношения к тому или иному явлению. С ростом аудитории Интернет становится средством не только массовой, но и глобальной коммуникации, перешагивающей через национальные границы и
\end{abstract}


объединяющей мировые информационные ресурсы в единую систему.

В современной антропоцентрической когнитивно-дискурсивной парадигме все более убедительно отстаивается утверждение о том, что будущее науки заключается в многоаспектном, комплексном исследовании феноменов мира. Требования интеграции лингвального, психологического и социокультурного в лингвистических исследованиях выдвигают на первый план изучение человека как биокогнитивносоциальной системы, его сознания, мышления, эмоций, материализированных в условии существования языка. Особым научным интересом пользуется проблема концептуализации и вербализации эмоций.

Английский язык сегодня стал одним из главных языков международного общения. В современном

Интернет-пространстве английский язык также занимает лидирующие позиции. Вместе с тем, в условиях глобализации и развития кросскультурной коммуникации, в английском языке концептуализируются понятия, которые являются основополагающими для других культур и этносов. Особенно ярко в англоязычном электронном дискурсе репрезентирован концепт «Muslim World».

\section{Материалы и методы исследования.}

Материалом исследования, помимо теоретических постулатов в данной области, стал фактический материал следующих электронных СМИ: Al Jazeera: Live News, CNN International edition.

Исследование было основано на таких методах, как сравнительно-сопоставительный, метод компонентного анализа, но основным был выявлен метод дефиниционного анализа лексических единиц.

\section{Основное содержание исследования.}

Исследуя особенности формирования концепта «Muslim World», приходим к выводу, что наиболее распространенной единицей, репрезентирующей концепт «Muslim World» является «terrorism». При этом, формируется ее концептуальное поле, как и у «Muslim World», через концептуальные признаки.

Отметим, что ранее нами были выделены релевантные признаки концепта «Muslim World». Концепт, как и любая идентичная эпистемическая ментальная структура, формируется семью классами признаков: мотивирующим признаком слова репрезентанта концепта, образными признаками (выявляемыми через сочетаемостные свойства слова репрезентанта концепта), понятийными признаками, объективированными в виде семантических компонентов слова репрезентанта концепта, а также синонимами, функциональными признаками (отображающими функциональную значимость референта, скрывающегося за концептом), категориальными признаками (дименсиональными, квалитативными, квантитативными, ценностно-оценочными, пространственными и временными), символическими признаками - выражающими сложные мифологические, религиозные или иные культурные понятия, закрепленные за словом - репрезентантом концепта, ироническими признаками (выражающими утрату ценностного компонента в структуре концепта, которая в концептуальной картине мира первоначально существовала). Понятие есть часть концепта; понятийные признаки входят в структуру концепта. Процессы концептуализации и категоризации тесно взаимосвязаны и взаимопереплетены между собой. Эти процессы помогают нам вычленить некий объект - реально или виртуально существующий - из общего фона подобных объектов, наделить его общими с другими и присущими только ему одному признаками [1, c. 17].

Культурно маркированная дихотомия «свой-чужой» выступает одной из фундаментальных бинарных оппозиций и лежит в основе формирования культурной, идеологической идентичности. В противопоставлении «Запад-Восток» можно увидеть отражение отношений между соответствующими сторонами, при этом происходит «концептуализация участников 
конфликта в терминах базовых ценностей «добра» и «зла»: террористы (мусульмане, исламисты) и их пособники - «зло»; Америка - «добро»; война с терроризмом это борьба добра со злом» [2, с. 33].

Противостояние

концептуальных признаков актуализируется в контексте «свойчужой» отражается в лингвальном феномене войны языковых знаков, включающих войну формы языковых знаков и войну содержания языковых знаков. Так, война формы языковых знаков предусматривает использование противоположными сторонами различных языковых средств для обозначения одних и тех же субъектов, событий, явлений. Иллюстрацией данного явления в английском языке есть новейшая поговорка: One man's terrorist is another man's freedom fighter. To есть один и тот же человек может одновременно рассматриваться и как террорист, и как борец за свободу в зависимости от того, на стороне какой из сторон конфликта он находится.

Другими примерами феномена войны формы языковых знаков выступают такие языковые единицы, как: suicide bomber, homicide terrorist $\leftrightarrow$ shahid, mujahideen, jihadist. Следует заметить, что приведенные номинации используются и «западной», и «восточной» сторонами, правда, при этом они несут разную денотативно-коннотативную нагрузку. Отчасти при этом происходит «манипуляция» семантикой, которая заключается в феномене, который мы именуем войной содержания языковых знаков. Это явление предполагает субституции семантики номинаций, когда в результате различного толкования противниками одних и тех же понятий слово приобретает иное значение. Представители атлантической цивилизации называют ультрарадикальных лиц языковыми единицами, отражающих их религиозно-идеологические убеждения (Islamist terrorist, jihadist terrorist), тактику (suicide-homicide terrorist, suicide / homicide bomber, car bomber, suicide murderer, sleeper agent), иерархический статус в ячейке (mega-terrorist, superterrorist, arch-terrorist).
Для номинации экстремистов в английском языке наряду с собственно английскими средствами параллельно функционируют заимствования из арабских языков (shahid, mujahideen, jihadist) и их англоязычные соответствия (martyr, holy warrior), причем как эти заимствования, так и их соответствия в языке-реципиенте приобретают негативную коннотацию. Война содержания языковых знаков предусматривает различное толкование противниками одних и тех же единиц, что приводит к рефреймингу модуса, который, в свою очередь, вызывает смещение концептуальных признаков. Термин «рефрейминг» был взят из практической нейропсихологии, под которым мы будем понимать процедуру переосмысления и перестройки механизмов восприятия значения языковой единицы. Так, положительно маркированные единицы меняются на негативные (Eng .: shahid = suicide bomber, jihadist $=$ terrorist), а единицы c негативной окраской приобретают положительную коннотацию (Arab .: suicide bomber $=$ shahid $=$ martyr $)[4$, c. 10$]$.

$$
\text { «Terrorism» выступает важным }
$$

макросоциальным фактором, который активизирует инновационные языковые процессы. Заметим, что в ходе исследования процессов обогащения словарного состава языка ученые оперируют термином «неологизм», рядом с которым также функционируют такие понятия, как «лексическая инновация», «некодифицированная лексика», «неосема». Мы разделяем мнение Ю.А. Зацного, что неологизмами в английском языке выступают слова и словосочетания, которые воспринимаются носителями языка отдельного национального варианта как новые (по форме или по содержанию).

Актуализация концепта «Muslim World» в массовом сознании, как показывает представленный ниже анализ фактического материала, происходит под влиянием коммуникативных стратегий манипуляционного характера. Так, в ведущих англоязычных масс-медиа нами были 
зафиксированы такие языковые единицы, как: anti-Western jihadist; the Great Satan; the Islamic bomb; Islamic extremism; Islamic militant; Islamic terrorist; Islamist violence; Islamofascism; Jihadist terrorism; militant cleric; militant Islam; militant Islamic terrorist; Muslim military powers; panIslamism; radical imam; radical Islamism; religious extremism; religious fanaticism; violent Islamism; violent jihadist; the «WMDnation» и др. Bce они вербализируют концепт «Muslim World» таким образом, что в сознании немусульман формируется предвзятое отношение к представителям этой мировой религии, их образу жизни, религиозным и культурным ценностям.

Более того, презентация ключевого понятия ислама - джихада - в таких комбинациях слов, как: bigoted jihad; global jihad; Islamic jihad; suicide jihad и т.д., меняет вектор его действия в диаметрально противоположную сторону от «борьбы со злом в своей душе» до «глобальной борьбы против всех немусульман мира». Об истинных причинах такого радикального изменения в трактовке этого понятия можно только догадываться. Однако, по нашему мнению, в данном случае мы видим результат действия всех возможных факторов - и манипуляции человеческим сознанием через средства массовой коммуникации, и элементарная безграмотность представителей масс-медиа, которые отвечают за отбор и презентацию информации, и уже сформированный в сознании немусульман стереотип вооруженного религиозного фанатика.

В качестве ответной реакции во многих развитых странах мира, где в больших количествах проживает мирное мусульманское население, возникло движение «Muslim protest against terrorism», которое имеет целью не только просветительскую деятельность по поводу разъяснения неверно понимаемых коранических принципов, но и активное противостояние через средства массовой коммуникации религиозному фанатизму во всех его проявлениях. Эти и другие факты свидетельствуют об использовании в англоязычных СМИ многочисленных манипуляционных стратегий, которые играют активную роль не только в процессе вербализации тех или иных концептов, в частности - «Muslim World», но и в целенаправленном навязывании немусульманскому обществу негативной оценки мирных и вполне законопослушных его граждан, исповедующих ислам. Это явление уже получило название Islamophobia «предвзятое отношение к лицам, исповедующих ислам, как результат антимусульманской пропаганды».

Ещё одно понятие, которое репрезентирует рассматриваемый концепт, это понятие власти, которая максимально позиционируется через телеканалы Al Jazeera и $C N N$ в мусульманском мире. При этом мусульманская власть обобщается и подается как что-то целостное без разграничения по странам. СМИ активно используют стратегию апелляции к авторитету лица (этос), чтобы предоставить убедительность и валидность информационного сообщения. Одной из тактик в рамках стратегии апелляции к авторитету лица является тактика манипуляции информацией. Она заключается в том, что сообщение, прозвучавшее из авторитетного источника, трактуется поразному, исходя из идеологической парадигмы того или иного телеканала. Разная идеологическая окрашенность сообщений, которая прослеживается при анализе материалов двух информационноаналитических телекомпаний, вызвана, прежде всего, желанием способствовать выработке у реципиента такой модели мира, которая изначально соотносилась бы с политикой телекомпаний.

Так, говоря о намерении Палестинской автономии обратиться в Совет Безопасности $\mathrm{OOH} \mathrm{с} \mathrm{просьбой} \mathrm{признать} \mathrm{ее} \mathrm{как} \mathrm{независимое}$ государство, телеканал $C N N$ подает это событие, как одностороннее решение палестинской власти, «цитатой» при этом являются слова советника главы Палестинской национальной администрации: Palestinians are turning to the United Nations as frustration mounts over the lack of progress towards a Middle East peace. Chief Palestinian 
negotiator says they will ask the UN Security Council to endorse a unilateral declaration of independence [9]. Языковая единица unilateral, благодаря актуализации значения decision or action taken by only one of the groups, organizations, or countries that are involved in a particular situation without the agreement of others, способствует формированию негативного отношения к действиям власти со стороны реципиентов.

Al Jazeera, в свою очередь, делает акцент на том, что такое решение палестинской власти не является односторонним, а вместо этого таким, что нашло поддержку большинства арабских стран, для подтверждения этого дает развернутую цитату советника: The Palestinian government in the West Bank is planning to ask the United Nations Security Council to endorse an independent state, with peace talks staled yet again over the issue of settlement building by Israel ... This is not a Palestinian unilateral declaration. This is a Palestinian decision backed now with Arab foreign ministers meeting last Thursday that we should seek to go to the Security Council to have the Security Council recognize the Palestinian state on the 67 border with East Jerusalem as its capital. Языковая единица backed, благодаря актуализации значения supported, advocated, способствует усилению положительной оценки действий Палестинской власти, что является прямо противоположным сообщению, которое прозвучало на телеканале Си-Эн-Эн.

В рамках данной стратегии используется также тактика предоставления / осуждения действий, которая осуществляется не прямо, а опосредованно, то есть через авторитетный источник, на который, собственно, и ссылается другая телекомпания. Говоря об очередной схватке, в результате которой погибло трое палестинцев, Си-Эн-Эн оправдывает действия военных, подавая убийство как возмездие за смерть израильтянина: The first incident happened in the West Bank city of Nablus, where the Israeli military killed three Palestinians it said were responsible for the death of an Israeli civilian in the West Bank this week [9]. Возлагая вину за убийство военных, Си-Эн-Эн одновременно смещает акцент с главного события, обосновывая правомерность таких действий.

Al Jazeera, зато осуждает действия израильских военных, заявляя о том, что убитые палестинцы были гражданскими, которые всего лишь собирали металлолом на границе: An Israeli military spokeswoman confirmed that soldiers shot and killed three Palestinians suspected of trying to infiltrate from Gaza, which is governed by Hamas. However, a Hamas security source said the three were apparently civilians collecting scrap metal in an industrial zone near the Israeli border [8]. Отрицательная оценка эксплицируется через использование синонимичных языковых единиц shot и killed, которые, благодаря актуализации значения to fire a bullet hit, injure and kill a person и to make innocent people die, усиливают иллокутивную силу высказывания.

Вышеприведенный пример может служить одновременно и демонстрацией тактики использования активного / пассивного состояния, как способа перекладывания вины на одну из сторон конфликта. Когда в сообщении речь идет о событии, которое имело негативные последствия, использование активного состояния усиливает вину той или иной стороны, а пассивного - смягчает высказывания. Для иллюстрации этого утверждения приведем следующий пример: Several people were killed and more than 300 were arrested in anti-government protests in Tehran Sunday, Iran's Deputy Police Chief Ahmad Reza Radan said on state television station IRINN. The toll was the result of clashes that broke out between demonstrators and security forces as large crowds gathered for Ashura, a major religious observance [9]. Из данного сообщения вполне понятно, что именно полиция арестовала протестантов и несет ответственность за убийство иранцев, однако пассивное состояние и речь о том, что схватка разгорелась между демонстрантами и офицерами спецслужбы between demonstrators and security forces, a не наоборот, способствует созданию 
положительного образа офицеров, которые выступили «защитниками правопорядка» и «негативного образа демонстрантовнарушителей».

Al Jazeera, в противовес Си-Эн-Эн, говорит о том, что именно полиция была инициаторм столкновения: Iranian police have clashed with thousands of opposition supporters in Tehran during a Shia religious ceremony, witnesses in the Iranian capital said. Sources told Al Jazeera that nearly 3,000 people had gathered on Saturday in northern Tehran, where Mohammad Khatami, the former president, was expected to deliver a speech. The event was later cancelled as police fired tear gas and used batons to disperse the crowd [8]. Позиционирование иранской полиции как активной стороны происходит путем использования языковых единиц clash - to come into conflict, fire tear gas - irritate the eyes and cause blinding tears и use baton apply a thick heavy stick as a weapon в активном состоянии.

Стратегия апелляции к разуму (логос) может реализоваться с помощью ряда тактик, одной из которых является тактика концептуального отражения действительности. Она заключается в том, что аргументация происходит путем использования языковых единиц, входящих в номинативное поле того или иного концепта. Под концептом мы понимаем дискретное ментальное образование, базовую единицу мыслительного кода человека, имеющего относительно упорядоченную внутреннюю структуру, и являющегося результатом познавательной (когнитивной) деятельности личности и общества [6, с.34].

Выясняя причины убийства майором Маликом Хасаном 13 человек на техасской военной базе Форт-Худ, Си-Эн-Эн объясняет аномальное поведение с помощью таких языковых единиц, как treatment, trauma, stressful, to pick up symptoms: It is an open secret that most of the military brass and many of the soldiers are openly complaining that they are not getting adequate treatment. People are repeatedly being deployed, they are going on many more tours than anticipated, and the more you are exposed to trauma, the more stressful the situation, the more prone you are to pick up symptoms [9].

Зато Al Jazeera аргументирует поступок Малика Хасана тем, что он был совершен под влиянием страха участвовать в военной кампании в Афганистане и Ираке: At Port Hood the deeper impact of the horror of war are thought to be particularly acute. It's the largest US army base in the country and units here have seen some of the fiercest fighting in Iraq and Afghanistan. Some believe suspected gunman Nidal Hasan became petrified of deploying after counselling soldiers here and his previous job at Walter Reed medical centre [8]. Это проявляется, прежде всего, в употреблении языковых единиц the horror of war, acute, the fiercest fighting, которые входят в номинативное поле концепта «Muslim World».

Еще одной тактикой, направленной на апелляцию к разуму, является тактика использования аналогий, которая направлена на усиление / ослабление иллокутивной силы высказывания. Продолжая расследование по делу майора Малика Хасана, была обнаружена его переписка с Имамом аль Анваром, который имел отношение к АльКаиде: US military officials say that intelligence agencies intercepted communications of Nidal Hasan to a Yemeni cleric Anwar al-Awlaki and shared them with other US government agencies. Al-Awlaki is mentioned in the 9/11 commission report as having developed a close relationship with two $9 / 11$ hijackers ... This is the guy well known in terrorist circles and very supportive of terrorism in the past. A blog believed to be written by Al-Awlaki praises Nidal Hasan as a hero "a man of conscience who could not bear living the contradiction being a Muslim and serving in an army that is fighting against his own people [9]. Языковая лексема intercept, благодаря актуализации значения to stop, deflect, or seize on the way from one place to another и prevent something illegal from arriving or proceeding, создает впечатление незаконности этой переписки, а проведение аналогии между майором Маликом Хасаном и Имамом Аль-Анваром - человеком, 
который имел отношение к Аль-Каиде, усиливают негативную окраску сообщения.

Al Jazeera взамен отмечает, что переписка Малика Хасана с Имамом Аль-Анваром было лишь частью профессионального долга, которую тот выполнял работая психиатром на военной базе Форт-Худ: Intelligence agencies were investigating major Nidal Hasan in December of last year. They reviewed what's believed to be email communication between Hasan and a Muslim cleric in Yemen who is known for his anti-American teachings. Anwar al-Awlaki served as an imam outside the Washington DC where Hasan worshiped. In a blog posting on his website on Monday Awlaki wrote "Nidal Hasan is a Hero. He is a man of conscience who could not bear living the contradiction being a Muslim and serving in an army that is fighting against his own people». Federal officials said they ended the investigation after concluding that Hasan's communications were related to research he needed to do as a psychiatrist at the Walter Reed Medical Centre [8]. Называя переписку между Маликом Хасаном и Имамом Аль-Анваром what's believed to be email communication, Al Jazeera утверждает, что было бы ошибочным называть это перепиской, тем самым смягчая иллокутивную силу высказывания. Стратегия апелляции к эмоциям (пафос) реализуется с помощью политики формирования отношения к сообщению путем апелляции к позитивным или отрицательным эмоциям.

Си-Эн-Эн, говоря о столкновении офицеров спецслужбы с палестинцами, формирует негативное отношение реципиента к последним, указывая на их жестокость, о чем свидетельствуют языковые единицы clashed, wounded, dead, violence: Palestinians clashed with Egyptian security forces along the Gaza border Wednesday over the delay of an expected aid convoy, leaving dozens of Palestinians wounded and one Egyptian soldier dead. В данной информации сообщении Си-Эн-Эн отмечает, что именно палестинцы ответственные за стычку, о чем свидетельствует следующая цитата: The Hamasorganized rally began peacefully but degenerated into violence with hundreds of Palestinians throwing rocks across the border wall [9].
Al Jazeera освещает это событие подругому: At least one Egyptian border guard has been killed and 35 Palestinians wounded along the Gaza border during fierce clashes with Egyptian security forces. A border protest on Wednesday turned violent over frustration that the aid convoy, Viva Palestina, had been delayed [8]. Апеллируя к жестокости, эта телекомпания, в отличие от Си-Эн-Эн, не налагает ответственности за стычку на палестинцев, а лишь констатирует ее факт.

Пытаясь вызвать чувство эмпатии, и быть более убедительной, Al Jazeera прибегает к применению тактики приближения к адресату, которая реализуется путем использования единиц разговорного стиля, эмотивной лексики. Говоря о выселении палестинцев из их жилья израильтянами, $A l$ Jazeera апеллирует к сочувствию, вместе с тем изображая израильтян агрессорами: It's becoming a familiar scene in East Jerusalem: Jewish settler taking over a Palestinian home and dumping the furniture in the garden. A Palestinian family built this home several years ago but they were never allowed to move in. Используя противопоставления, Al Jazeera акцентирует внимание на различия положения израильтян и палестинцев на оккупированной территории: The Israeli authorities said it had been built illegally; illegal for Palestinians maybe, but clearly a different law applies to Jews since settlers are now inside [8].

Си-Эн-Эн освещает это событие подругому, указывая на полную правомерность занятия израильтянами помещений, которые до недавнего времени были собственностью палестинцев: «Settlers and Palestinians face off over property claims. Jewish settlers move in to a building in an Arab neighbourhood of east Jerusalem. They say this is their land and Israeli judge gave them the key to this part of the property» [8]. Как видим, Си-Эн-Эн избегает использование эмотивно-окрашенной лексики и лишь констатирует тот факт, что израильтяне действовали в соответствии с законом.

\section{Результаты исследования.}

Проанализированный материал дает нам основания считать, что Ислам вызывает негативные ассоциации и в последнее время наблюдаются изменения относительно восприятия Ислама. Концепт «Muslim World» 
объективируется

B

современном коммуникативном Интернет пространстве в основном в негативном свете, указывая на его жесткость, разрушительную силу и угрозу обществу. По нашему мнению, это является результатом недостаточной информированностью общества о культурном наследии Исламского мира, его обычаев и ключевых понятий. Следует обращать особое внимание на представление тех или иных событий в различных СМИ.

Таким образом, мы пришли к выводу, что концепт «Muslim World» представляет собой динамичный продукт дискурса, отражаемый в виртуальном коммуникативном пространстве. Дальнейшее исследование способствует более полному пониманию современной англоязычной картины мира, углубляет научные представления о взаимодействие политических и этнических событий с языком и культурой молодёжи Британии.

Печатается при поддержке Гранта Президента для государственной поддержки молодых российских ученых докторов наук РФ МД-2687.2017.6 «Вариативность английского языка Великобритании в условиях влияния политического, социального и экономического факторов (на материале Интернет-дискурса)».

Supported by the President's Grant for the state support of young Doctors of Sciences of the Russian Federation MD-2687.2017.6 "The variability of the English language in Great Britain influenced by political, social and economic factors (based on Internet discourse)."

Информачия о конфликте интересов: авторы не имеют конфликтов интересов для декларачии.

Information of conflict of interests: authors have no conflicts of interests to declare.

\section{Список литературы}

1. Буряковская В.А. Признак этничности в семантике языка (на материале русского и английского языков): Дис. ... канд. фил. наук. Волгоград, 2000. 209 с.

2. Григорьева В.С. Дискурс как элемент коммуникативного процесса: прагмалингвисти- ческий и когнитивный аспекты: монография. Тамбов: Тамб. гос. техн. ун-т, 2007. 288 с.

3. Егорин А.З., Ульченко Н.Ю. Ислам и общественное развитие в начале XXI века. М.: Крафт+, 2015. 496 c.

4. Маслова В.А. Когнитивная лингвистика: учебное пособие. Минск: Тетра Системс, 2004. $256 \mathrm{c}$.

5. Мусульмане в публичном пространстве Америки: Надежды, опасения и устремления. Пер. с англ. И. Мюрберг URL: http: //www.igpi.ru/bibl/other_articl/muslims_in_america/ (дата обращения: 15.07.2017).

6. Попова З.Д., Стернин И.А. Когнитивная лингвистика. М.: АСТ: Восток-Запад, 2007. 314 с.

7. Стернин И.А. Когнитивная интерпретация в лингвокогнитивных исследованиях // Вопросы когнитивной лингвистики. 2004. № 1. С. 65-70.

8. Al Jazeera: Live News. URL: http://www.aljazeera.com/ (дата обращения: 20.07.2017).

9. CNN International edition. URL: http://edition.cnn.com/ (дата обращения: 20.07.2017).

10. Islamophobia and right-wing terrorism. URL: http://articles.latimes.com/2012/ sep/01/opinion/la-le0901-postscript-islamophobia-20120901 (дата обращения: 25.07.2017).

11.Jerichow A., Simansen J.B. Civilizations: Clash or Cooperation? Islam in a changing world. Europe and the Middle East - Routledge, 2013. 220 p.

12. Tibi B. The challenges of fundamentalism: political Islam on the new world order. Berkley, Los Angeles, London: University of California Press, 2012. 293 p.

\section{References}

1. Buryakovskaya V.A. A sign of ethnicity in semantics of the language: On the Russian and English material. Volgograd, 2000. 209 p. [in Russian].

2. Grigorieva V.S. Discourse as an element of the communicative process: pragmalinguistic and cognitive aspects: monograph. Tambov: Tamb. State. Tech. University, 2007. 288 p. [in Russian].

3. Egorin A.Z, Ulchenko N.U. Islam and social development in the early 21st century. Moscow: Kraft+, 2015. 496 p. [in Russian].

4. Maslova V.A. Cognitive Linguistics. Minsk: Tetra Sistems, 2004. 256 p. [in Russian].

5. Muslims in the public space of America: Hopes, fears and aspirations. Translation from English by I. Mürberg. URL: http://www.igpi.ru/bibl/other_articl/muslims_in_amer ica/ (Date of access: July 15, 2017). [in Russian]. 
6. Popova Z.D, Sternin I.A. Cognitive linguistics. Moscow: AST: Vostok-Zapad, 2007. 314 p. [in Russian].

7. Sternin I.A. Cognitive interpretation in linguocognitive studies // Questions of cognitive linguistics. 2004. № 1. P. 65 - 70. [in Russian].

8. Al Jazeera: Live News. URL: http://www.aljazeera.com/ (date of access: July 20, 2017). [in English].

9. CNN International edition. URL: http://edition.cnn.com/ (date of access: July 20, 2017). [in English].

10. Islamophobia and right-wing terrorism. URL: http://articles.latimes.com/2012/ sep/01/opinion/la-le-0901-postscript-islamophobia20120901 (date of access: July 25, 2017). [in English].
11. Jerichow A., Simansen J.B. Civilizations: Clash or Cooperation? Islam in a changing world. Europe and the Middle East - Routledge, 2013. 220 p. [in English].

12. Tibi B. The challenges of fundamentalism: political Islam on the new world order. Berkley, Los Angeles, London: University of California Press, 2012. 293 p. [in English].

\section{Козырева Марина Константиновна,} аспирант.

\section{Kozyreva Marina Konstantinovna,} Postgraduate Student. 